\title{
Functional and cognitive changes in community-dwelling elderly: Longitudinal study
}

\author{
Carolina S. Figueiredo ${ }^{1}$, Marcella G. Assis ${ }^{2}$, Silvia L. A. Silva ${ }^{3}$, \\ Rosângela C. Dias ${ }^{4}$, Marisa C. Mancini ${ }^{2}$
}

\begin{abstract}
Background: The relationship between aging and increased life expectancy in the overall population likely contributes to a higher frequency rate and incidence of illnesses and functional disabilities. Physical dependence and cognitive impairment might hinder the performance of activities and result in an overload of care duties for the patient's family and the healthcare system. Objective: The aim of this study was to compare the functional and cognitive changes exhibited by the elderly over a 6-month period. Method: This longitudinal and observational study was conducted in a sample of 167 elderly people, who were selected from the database of the Network of Studies on Frailty in Brazilian Elderly, Universidade Federal de Minas Gerais - UFMG. The participants submitted to the Mini Mental State Examination (MMSE), Katz Index, Lawton and Brody's scale and responded to items on Advanced Activities of Daily Living (AADLs). We analyzed the data using multivariate regression models. Results: The participants' functional capacity exhibited reduced performance of specific instrumental activities of daily living (IADLs), $\mathrm{p}=0.002$, and basic activities of daily living (BADLs), $\mathrm{p}=0.038$. Living alone (odds ratio (OR), 2.53; 95\% confidence interval (CI), 1.09-5.87) and work status (OR, 2.52; 95\% CI, 1.18-5.41) were associated with changes in the IADLs. The scores in the AADL scale $(\mathrm{p}=0.163)$ and MMSE $(\mathrm{p}=0.059)$ did not exhibit any significant difference during the study period. The participants with better cognitive function were more independent in their performance of AADLs and IADLs. Conclusion: The results depict specific patterns of loss and stability of functional capacity in community-dwelling elderly.
\end{abstract}

Keywords: elderly; activities of daily life; cognition; rehabilitation.

\section{HOW TO CITE THIS ARTICLE}

Figueiredo CS, Assis MG, Silva SLA, Dias RC, Mancini MC. Functional and cognitive changes in community-dwelling elderly: longitudinal study. Braz J Phys Ther. 2013 May-June; 17(3):297-306. http://dx.doi.org/10.1590/S1413-35552012005000094

\section{Introduction}

During recent decades, the world population entered a process of aging. In Brazil, the aging process is occurring rapidly in association with advanced life expectancy in the overall population, which might result in an increased prevalence and incidence of diseases and functional disabilities ${ }^{1}$.

According to the literature, functional limitations comprise one of the most important prognostic factors for mortality of the elderly ${ }^{2,3}$. From the epidemiological point of view, disability is usually measured based on reported difficulties or the need for assistance in the performance of the basic activities of daily living (BADLs) and instrumental activities of daily living (IADLs) ${ }^{4}$. As a rule, the greater the difficulty is to perform BADLs, the more severe the disability is ${ }^{5}$, thus suggesting a linear correlation between the severity of disability and the functional performance potential, which must be subjected to empirical confirmation.

BADLs consist of self-care tasks, such as eating and bathing ${ }^{6}$, whereas IADLs relate to the management of one's environment and involve the links between home and the external environment and tasks such as buying food, cooking meals, and managing one's finances ${ }^{7}$. The advanced activities of daily living (AADLs) comprise a third category, which includes voluntary social, occupational, and leisure activities ${ }^{8}$. Although the difficulty in participating in AADLs might not indicate the actual presence of functional impairment, this difficulty might denote the conditions for a future loss of function that might be actualized.

Cognitive dysfunction might interfere with the individual's ability to understand and integrate the

\footnotetext{
${ }^{1}$ Conviver Occupational Therapy Unit-Assistance Complex for Elderly, Belo Horizonte, MG, Brazil

${ }^{2}$ Graduate Program of Rehabilitation Science, School of Physical Education, Physical Therapy and Occupational Therapy,

Universidade Federal de Minas Gerais (UFMG), Belo Horizonte, MG, Brazil

${ }^{3}$ Physical therapist Instituição, Belo Horizonte, MG, Brazil

${ }^{4}$ Department of Physical Therapy, Graduate Program of Rehabilitation Science, School of Physical Education, Physical Therapy and

Occupational Therapy, UFMG, Belo Horizonte, MG, Brazil.

Received: 08/31/2012 Revised: 11/19/2012 Accepted: 12/18/2012
} 
various steps of the activities of daily living (ADL). Individuals with cognitive dysfunction might have problems with decision-making, performing individual tasks, and connecting information, in addition to requiring an excessive amount of time to perform tasks. Cognitive dysfunction is also related to the reduction of social relationships, which favors the development of isolation and depression ${ }^{9}$. To summarize, cognitive dysfunction might interfere negatively with the functional performance in every area of human life, including ADL (both social and interpersonal), work, and leisure activities.

There are few studies on the association between cognition and functional performance in the elderly in Brazil $^{10-12}$; the studies generally have cross-sectional designs as a rule. Longitudinal studies are required to produce evidence on the changes in the cognitive and functional performance of the elderly, conduct tests to assess how these changes occur over time to guide interventions and preventive actions, and, eventually, to contribute to the planning of public policies.

The aims of this study were to compare the functional and cognitive changes occurring in community-dwelling elderly over a 6-month period and to analyze the demographic variables associated with the increase, maintenance, and reduction of functional and cognitive outcomes.

\section{Method}

In this longitudinal, observational study, we performed measurements at two different time points with a 6-month interval between the time points. The study was based on data retrieved from the database of the FIBRA Network (Network of Studies on Frailty in elderly Brazilians, a health center of the Federal University of Minas Gerais/Rede de Estudo da Fragilidade em Idosos Brasileiros, Universidade Federal de Minas Gerais, UFMG) and a FIBRA Network subproject ${ }^{13}$. The FIBRA Network is a multicenter, multidisciplinary project, which involves four research groups that are linked to Brazilian universities (University of São Paulo at Ribeirão Preto, USP-RP; Federal University of Minas Gerais, UFMG; State University of Rio de Janeiro, UERJ; and University of Campinas, UNICAMP) and other partners.

A total of 613 elderly individuals, who were randomly selected by the lottery method, applied to the Brazilian Institute of Geography and Statistics (Instituto Brasileiro de Geografia e Estatística, IBGE) census sectors and were interviewed at the health center of the UFMG. The data from the IBGE
2000 census were used to calculate the number of participants in each sector based on the proportion of elderly people in the census sectors that corresponded to the city of Belo Horizonte. In this study, the sample comprised 167 community-dwelling elderly of both genders, aged $\geq 65$ years, who were randomly selected from FIBRA Network's original database and were reassessed 6 months later.

Individuals who were excluded from the study had the following conditions: cognitive impairment; transient or permanent bedridden status; wheelchair confinement; severe sequelae of stroke; and neurological disorders that hindered their performance on tests.

The FIBRA Network study was approved by the Research Ethics Committee (Comitê de Ética e Pesquisa, COEP) of UFMG, Belo Horizonte, MG, Brazil, protocol ETIC 187/07. All of the participants signed an informed consent form.

\section{Instruments and procedures}

The cognitive function of the elderly who were recruited from the FIBRA Network database was screened using the Mini Mental State Examination (MMSE). The MMSE scores ranged from 0 to 30; a lower value indicated a greater degree of cognitive impairment ${ }^{14}$. In the present study and in agreement with the work of Brucki et al. ${ }^{15}$, the participants who scored above the cut-off point corresponding to their schooling level minus 1 standard deviation (SD) remained in the study, whereas those who scored below the cut-off point on the MMSE were excluded from the study.

We collected the participants' sociodemographic data related to their physical health, habits (tobacco smoking and use of alcohol), perceived health, use of healthcare services, nutrition, level of physical activity, and functional capacity (performance of BADLs, IADLs, and AADLs), in addition to measurements of physical activity, anthropometric parameters, fatigue, and global life satisfaction. For this study, we used the data collected on sociodemographic parameters, functional capacity, and cognition.

The Katz Index of independence in ADL was used to collect the data on BADLs ${ }^{6}$. The total score of this scale ranged from 0 to 6 ; the lower value indicated a greater level of independence.

Lawton and Brody's scale was used to assess the degree of independence in the performance of IADLs ${ }^{7}$. The score for each item ranged from 1 to 3 , where 3 indicated independence. The total score ranged from 7 to 21 ; the higher value indicated the 
greater level of independence in the performance of activities.

The data on AADLs were collected from a 12item list related to participation in social activities, such as visiting friends and relatives; participation in social groups and meetings; cultural activities; political activities, such as participation in the board of organizations; religious activities, such as attending church; trips; work; and driving vehicles. This list of items was elaborated by one of the FIBRA Network researchers based on the questionnaire of the Berlin Ageing Study ${ }^{16}$. The score for each item ranged from 1 to $3 ; 1$ meant that the individual never performed the investigated activity; 2 meant that he discontinued that activity; and 3 meant that he currently performs that activity. The total score ranged from 12 to 36 ; the higher scores pointed to greater levels of independence ${ }^{17}$.

The examiners received specific training for conducting interviews in a uniform and standard manner to collect data and ensure quality and pertinent information.

\section{Statistical analysis}

The Wilcoxon test was used to compare the scores on the MMSE, BADL, IADL, and AADL scales between time points 1 and 2 , as well as the differences in the various categories of demographic variables over time. The Mann-Whitney (two categories) or Kruskal-Wallis test (more than two categories) was used to compare the various categories of demographic variables between time points 1 and 2 in each dependent variable. Nonparametric tests were used because the data exhibited an asymmetric distribution ${ }^{18}$. The effect size was calculated using 95\% confidence intervals (CIs).

The Spearman's rank correlation coefficient was calculated to investigate the association between the MMSE scores and the various functional scales in time points 1 and 2 .

The difference between the scores was calculated (score in time point 2 minus score in time point 1) in all of the variables that exhibited significant changes between the two investigated time points and classified under the following categories: increase (difference $>0$ ), no change (difference $=0$ ), and reduction (difference $<0$ ).

We performed univariate analyses (chi-square and Kruskal-Wallis tests) to test the association of independent variables that were likely to be included in the multivariate model with the three categories of each dependent variable.
The multivariate ordinal logistic regression models were used to test the association of these factors: gender; marital status; work status; living alone; schooling; number of children; and monthly income with the categories of change in MMSE, AADL, IADL, and BADL scales. Among the various ordinal regression models available, we selected the proportional-odds mode ${ }^{19}$ because the response variable is a continuous variable clustered in categories, as in the present study. This model provided one single odds ratio (OR) estimate for all of the compared categories due to the proportionalodds assumption. This assumption was tested for each individual variable, as well as in the final model. The model goodness-of-fit was assessed by means of a deviance statistic ${ }^{19}$.

The variables that exhibited $\mathrm{p} \leq 0.25$ in the univariate analysis were initially used to build the multivariate models. The OR of each covariable was calculated.

In all of the statistical tests, the significance level was established as $\alpha=0.05$. The statistical analysis was performed using SPSS software, version 15.0 (SPSS Inc., Chicago, IL, USA).

\section{Results}

From a sample of 167 participants, $67.1 \%$ were females, and the average age was 73.1 years (SD, 5.7; range, $65-95$ years). Approximately $54.5 \%$ of the participants were married or lived with a partner, whereas only $16.8 \%$ lived alone. Most participants were not working $(77.8 \%)$ and were pensioners (70.7\%). The median schooling was 4 years, with an average of 7.44 years among the males and 5.89 years among the females. The median monthly income was $\mathrm{R} \$ 800.00$ (Brazilian currency), and the median family income was $\mathrm{R} \$ 1,500.00$.

Table 1 describes the total scores on the MMSE, AADL, IADL, and BADL scales at the two investigated time points, the mean, and the $95 \% \mathrm{CI}$ of the effect size to compare the differences in the scales scores.

We found a significant difference between the two investigated time points in the following items of scale IADL: meal preparation $(p=0.041)$ and housekeeping $(\mathrm{p}=0.002)$. In both instances, the percentage of independence decreased, and the percentage of need for assistance increased. In the BADL scale, only the item continence exhibited a significant difference between the two investigated time points, with an increase observed in the reported dependence. 
Table 2 describes the group's performance based on the correlation of the scale scores at time points 1 and 2 and the following variables: gender; educational level; and age range.

We compared the scale scores between the investigated time points and obtained the following results: Relative to the MMSE scores, $34.7 \%$ of the sample exhibited reduced scores; in $19.8 \%$, the scores exhibited no change; and the scores increased in $45.5 \%$. Relative to the AADL scale, $46.1 \%$ of the sample exhibited reduced scores; in $17.6 \%$, the scores exhibited no change; and the scores increased in $36.4 \%$. Relative to the IADL scale, $28.5 \%$ of the sample exhibited reduced scores; in $58.8 \%$, the scores exhibited no change; and the scores increased in $12.7 \%$. Relative to the BADL scale, $12.3 \%$ of the sample exhibited reduced scores; in $63.6 \%$, the scores exhibited no change; and the scores increased in $24.1 \%$.

The factors associated with the changes found in the MMSE, AADL, IADL, and BADL scales, including marital status, work status (no income, working, retired/pensioner), living alone, age, schooling (number of years), number of children, and monthly income, were subjected to a univariate analysis. The results are described in Table 3.

Only the variable schooling exhibited a significant correlation with the changes found in the MMSE scale $(\mathrm{p}=0.036$ ). Although the three variables, namely, marital status, living alone, and schooling, were initially included in the multivariate model $(\mathrm{p}<0.25)$, none of them remained in the final model.

No variable exhibited a significant correlation with the changes found in the AADL scale. Only the variable monthly income was initially included in the multivariate model $(\mathrm{p}<0.25)$ but was not significant in the multivariate analysis.

Work status exhibited a significant correlation with the changes found in the IADL scale. On the BADL scale, only the variable age exhibited a significant correlation with the changes found $(\mathrm{p}<0.05)$. To assess the factors associated with increased scores in the BADL scale, we included the following variables in the model: gender; age; and income $(\mathrm{p}<0.25)$; however, none remained in the final model.

To assess the factors associated with increased scores in the IADL scale, we included the following variables in the model: marital status; work status; living alone; number of children; and monthly income $(\mathrm{p}<0.25)$. The variables living alone and work status remained in the final model. The results are described in Table 4.
The scores on the MMSE did not exhibit a significant correlation with the scores in the functional scales when the difference of scores between the two investigated time points was considered. However, a separate assessment of the correlation of the scores in the MMSE with the scores in the functional scales at each investigated time point (Table 5) revealed a significant correlation with AADL at both investigated time points and IADL at time point 2 .

\section{Discussion}

The results quantified and described the direction of the changes in the functional capacity of community-dwelling elderly over a 6-month period. The functional capacity associated with IADL (food preparation and housekeeping) and BADL (continence) decreased. The cognitive function did not exhibit a significant difference between the investigated time points.

The results of the IADL scale indicated increased dependence in the domains of food preparation and housekeeping over the investigated time period. Such an increase was greater among males, participants with $>5$ years of schooling, and age up to 79 years. The elderly are often prevented from performing these types of tasks to spare them the physical exertion required, and in the case of males, they may be unable to perform these tasks because of cultural reasons. A study conducted in São Paulo showed that males exhibited a reduced capacity to perform tasks, such as cleaning the house, cooking meals, and doing the laundry and ironing clothes, which indicates the interference of sociocultural factors, because those tasks are usually performed by women ${ }^{20}$. In this study, the analysis of the factors associated with the changes in IADL pointed out two variables regarding independence, namely, living alone and work status. The participants who lived alone exhibited odds that were 2.5 times higher of increasing their independence in the performance of IADLs. According to the literature, living alone might be an appropriate option for the elderly who strive to maintain their independence and autonomy ${ }^{21}$, in addition to motivating them to remain independent as a function of the lack of a partner to share in the ADLs. A study conducted with the elderly found a strong correlation between work and better indicators of autonomy and physical mobility, even after adjustments for age and other sociodemographic factors ${ }^{22}$.

On the BADL scale, the participants exhibited an increased dependence relative to the item continence, 


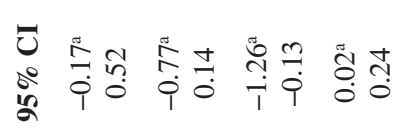

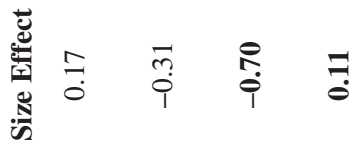

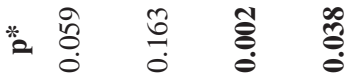

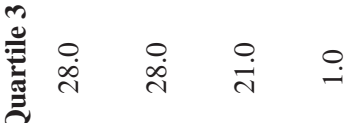
离

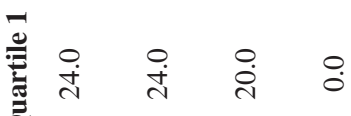
จ

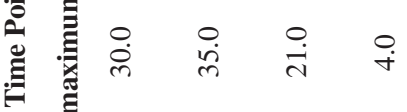

$\circ \quad \circ \quad 0$

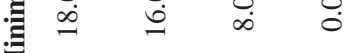

के $\stackrel{\text { i }}{m} \stackrel{\infty}{-} \stackrel{\circ}{\circ}$

हैं

z

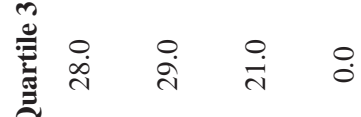

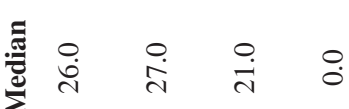

है

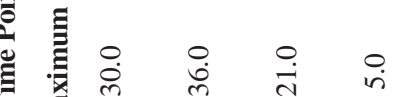

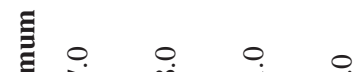

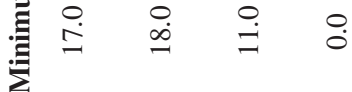

की $\stackrel{m}{m} \stackrel{3}{-} \stackrel{0}{0}$

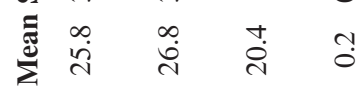

z $\stackrel{0}{\circ} \stackrel{8}{6}$

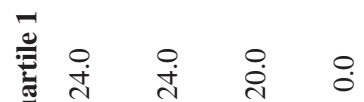

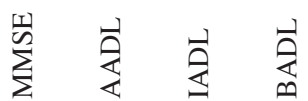

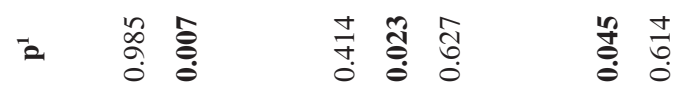

定

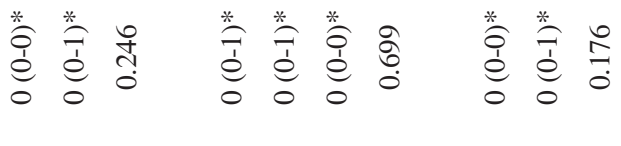

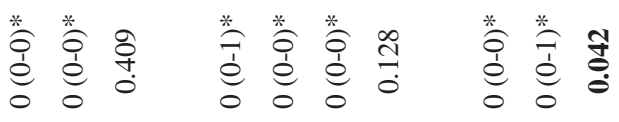

定

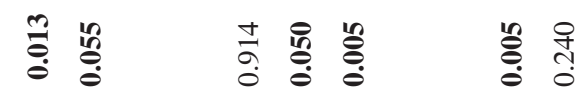

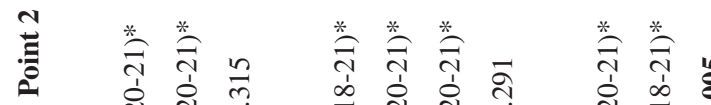

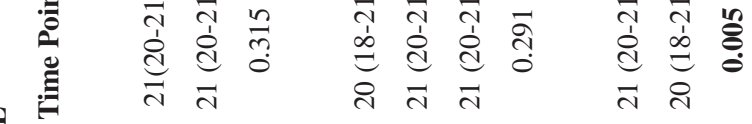

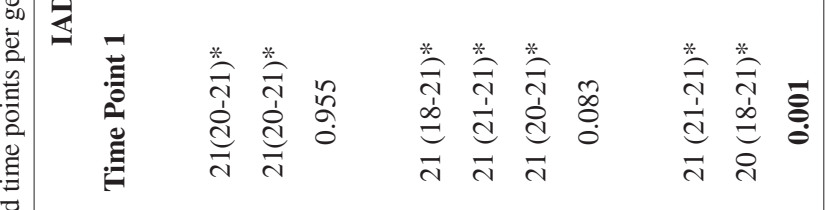

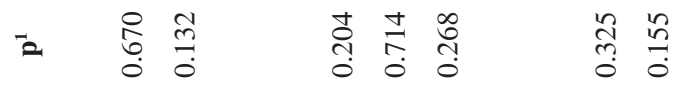

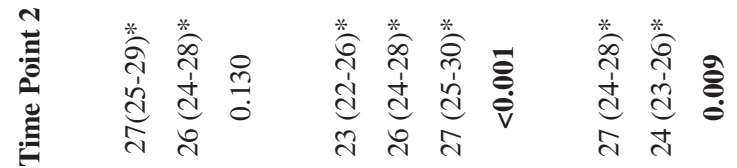
定

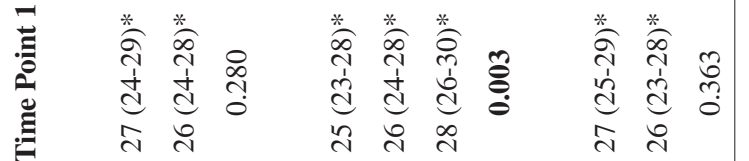

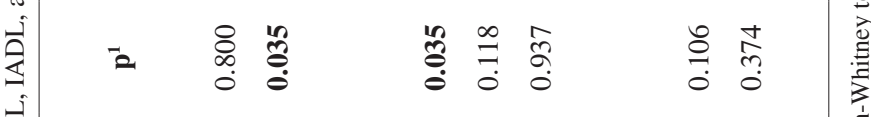

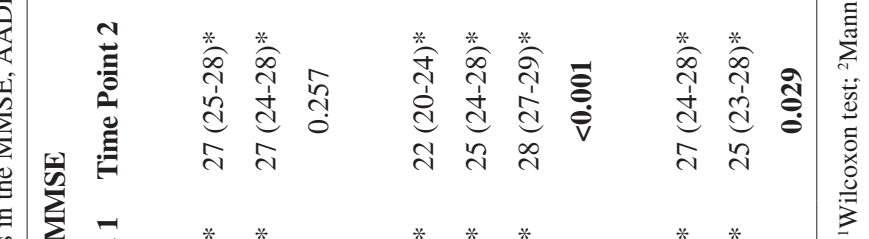

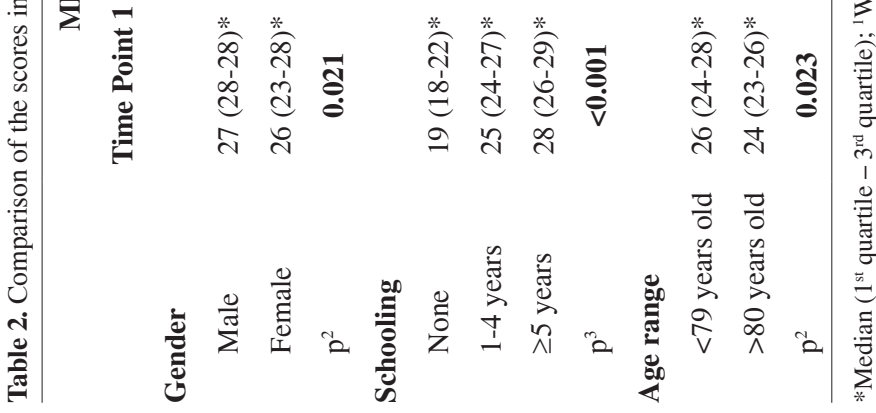




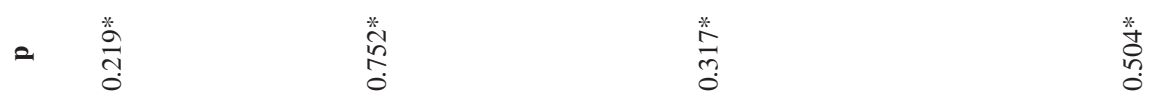

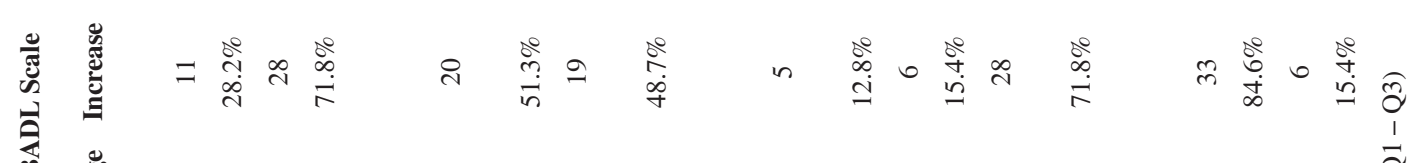

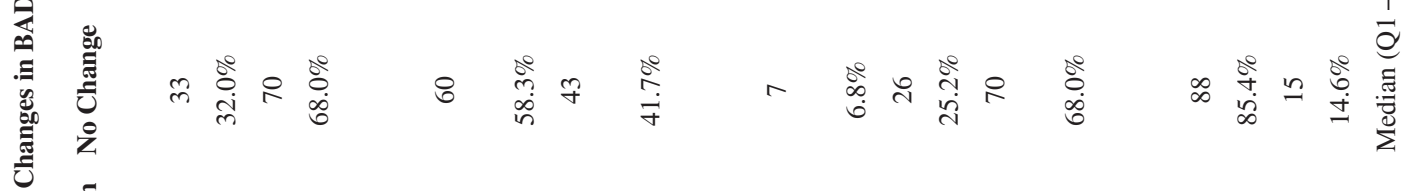

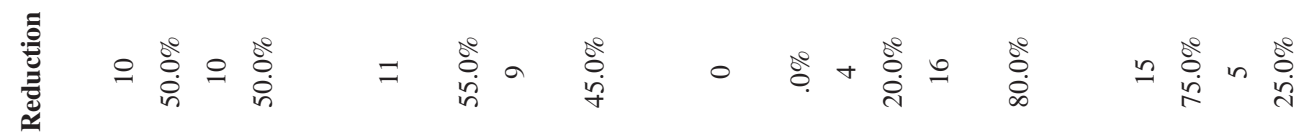

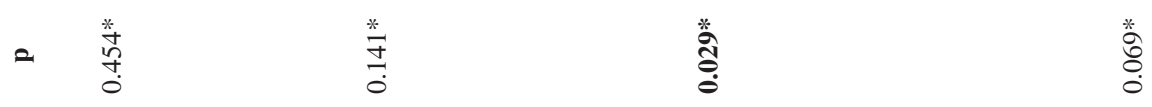

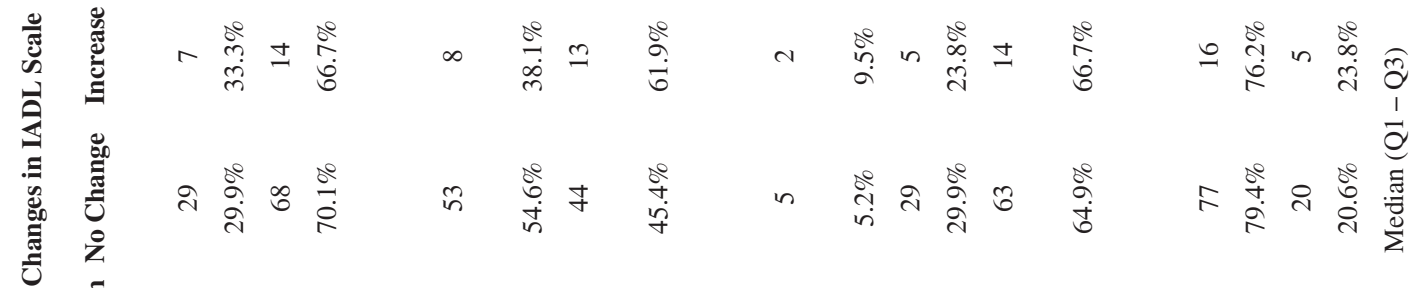

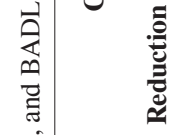

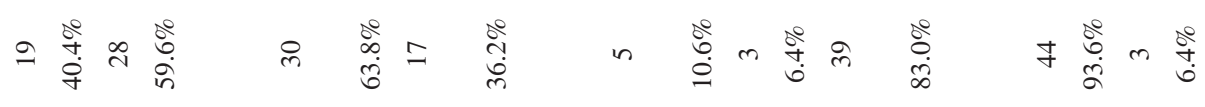

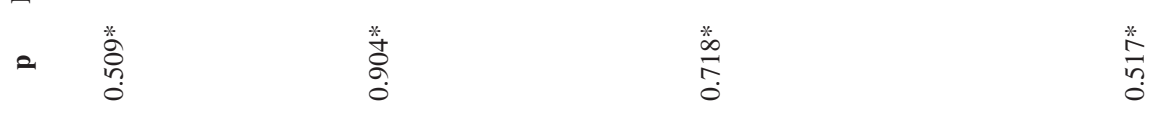

焉

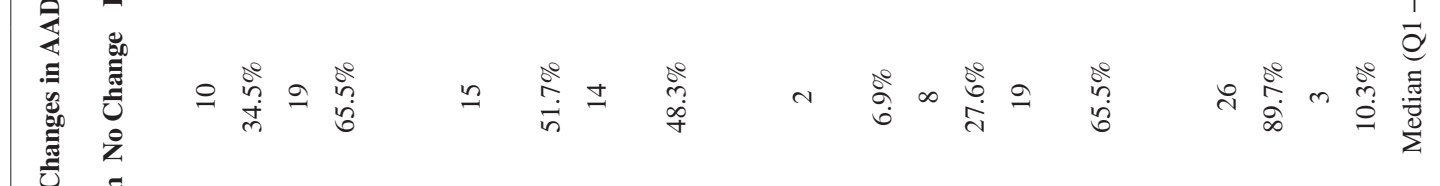

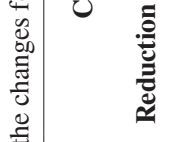

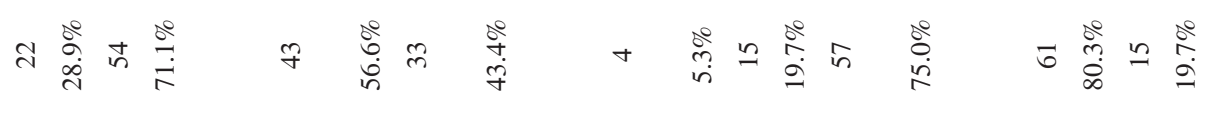
$=\underset{0}{0}$
$\frac{\text { 学 }}{0}$
苋
ले

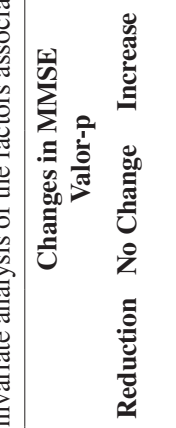

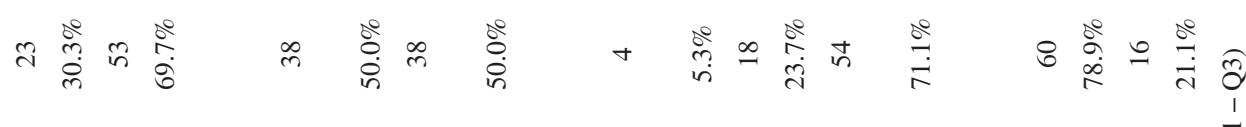

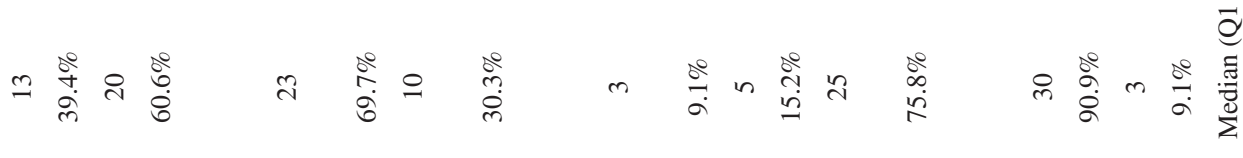

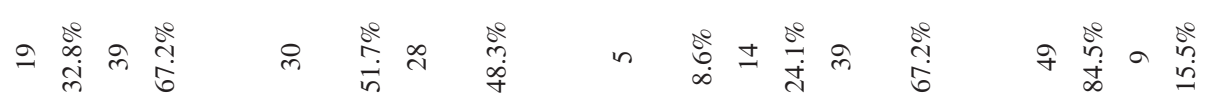

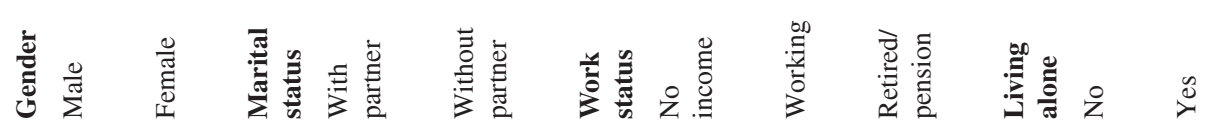




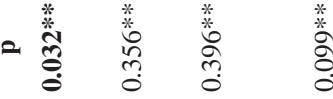

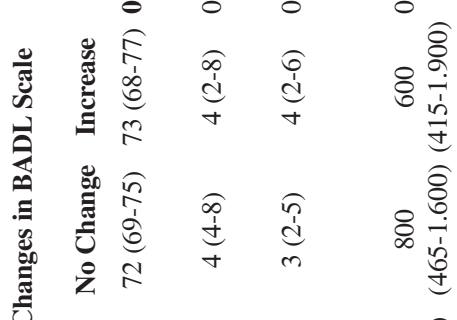

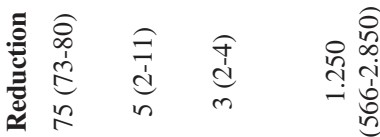

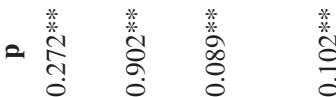

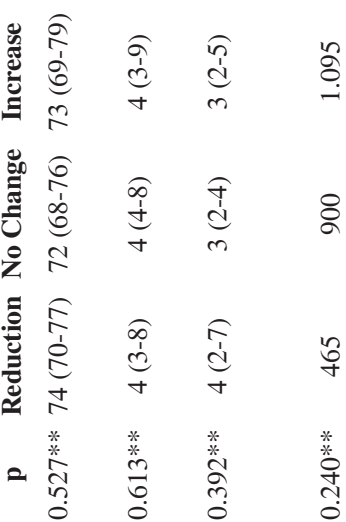

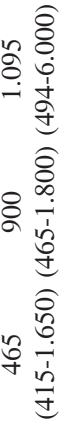

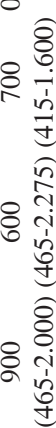

$=\frac{1}{r}$

苫
Table 4. Multivariate analysis (final proportional-odds model for ordinal logistic regression) of the factors associated with increased scores in the IADL scale.

OR

OR $95 \%$ CI

Living alone

No

Yes

$1.09 ; 5.87$

Work status

No income $\quad 1.00$

$0.31 ; 3.25$

Working

$1.18 ; 5.41$

Retired/pensioner

1.00

Deviance statistic $p$ value $=0.139 ;$ parallel lines test $p$ value $=0.067$; $\mathrm{CI}=$ Confidence Interval; OR = Odds Ratio.

Table 5. Correlation between the MMSE scores and scores in the activities of daily living scales.

MMSE

Time Point 1 Time Point 2

\begin{tabular}{ccc} 
AADL Correlation coefficient* & $\mathbf{0 . 2 6}$ & $\mathbf{0 . 2 0}$ \\
$\mathrm{P}$ & $\mathbf{0 . 0 0 1}$ & $\mathbf{0 . 0 1 2}$ \\
IADL Correlation coefficient* & 0.07 & $\mathbf{0 . 1 6}$ \\
$\mathrm{P}$ & 0.364 & $\mathbf{0 . 0 3 8}$ \\
BADL Correlation coefficient* & 0.06 & -0.10 \\
$\mathrm{P}$ & 0.434 & 0.221 \\
\hline
\end{tabular}

*Spearman's correlation coefficient.

which corroborates the results of the study conducted by Nunes et al. ${ }^{23}$. Aging might associate with pelvic floor weakness, which is one of the main factors associated with incontinence. Incontinence might lead to social isolation and low self-esteem; it might also interfere with the performance of IADL. The increased dependence related to continence was significantly greater among the women, participants with 1 to 4 years of schooling, and age up to 79 years. Virtuoso et al. ${ }^{24}$ observed that the prevalence of urinary incontinence was greater among women. Regarding schooling, Fiedler and Peres ${ }^{25}$ asserted that low levels of education were associated with a greater dependence in the performance of BADLs. In this study, the univariate analysis showed that the participants with increased independence in the performance of BADLs had a higher median age (75 years), which disagrees with the findings in the study by Lebrão and Laurenti ${ }^{26}$, who pointed to the higher odds of difficulty in the performance of BADLs together with increased age. The chronological age does not represent a precise marker of the changes associated with senescence because the elderly of a 
similar chronological age exhibit a wide variation in their health status, frequency of activities performed, and independence level. Additionally, the individual lifestyle and environmental features exert a substantial influence, which might facilitate or hinder the performance of BADLs. In the present study, no investigated factor exhibited an association with increased dependence in the performance of BADLs on the multivariate analysis.

No significant difference was found between the investigated time points in the AADL and MMSE scales. However, the $\mathrm{p}$ value was borderline in the latter, pointing to a tendency for increased scores among the women and less educated participants, who might have benefited from the learning opportunity provided by the tests because the present sample did not include individuals with cognitive disorders. Learning after the application of MMSE was also reported in the study by Lourenço et al. ${ }^{27}$ with 105 community-dwelling elderly. According to those authors, the attention paid by people to their own performance might be awakened by their repeated participation in tests, thus contributing to the test-enhanced learning effect. In the present study, we observed that variable schooling was associated with the changes found in MMSE on the univariate analysis. The scores of the participants with the highest education did not change, which agrees with the findings in the longitudinal study conducted by Argimon and Stein ${ }^{28}$, in which the elderly with the highest level of education maintained their high scores in the MMSE after 3 years of follow-up. These findings might be explained by the fact that the elderly with high levels of education tend to keep themselves informed and up-to-date on current events because they have access to newspapers and the Web. Because the MMSE assesses cognitive functions related with orientation, the elderly tend to maintain their cognitive performance levels. Nevertheless, no factor analyzed in the present study was associated with the changes in the MMSE on the multivariate analysis.

An analysis of the score difference as a function of schooling at each investigated time point showed that the scores on the MMSE and AADL increased at both time points together with an increase in schooling. The elderly with high levels of education might be more interested in and motivated to participate in several activities investigated in the present study, such as the cultural and political activities and driving vehicles, which might account for their higher scores on the AADL scale. Analysis of the score difference per gender at each investigated time point showed that the males scored higher on the MMSE at time point 1. Those findings might be explained by the fact that males had a more than average schooling and that the women in the investigated generation had less access to education. With regard to variable age, the participants $>80$ years of age exhibited significantly lower scores in the MMSE. Those results agreed with the findings by Diniz et al. ${ }^{29}$, in which schooling was one of the most influential factors on cognitive performance, males scored better on the MMSE, and the oldest participants exhibited poorer cognitive performance. In the present study, the participants $>80$ years of age exhibited a greater dependence in the performance of IADLs (both time points), AADLs (time point 2), and BADLs (time point 1) compared to the younger ones. Those results agreed with the findings in other studies, according to which the increase in age correlated with a greater functional disability ${ }^{10,25}$

An analysis of the correlation between the total MMSE score and the scores in the ADL scales at each investigated time point showed that the individuals with better cognitive performance were more independent in the performance of AADLs (both time points) and IADLs (time point 2). Those results agreed with the findings by Yassuda and Silva ${ }^{30}$, in which the participation in social activities (AADLs) might demonstrate beneficial effects in cognitive functions.

Among the limitations of the present study, there is the possibility of error in the classification of functional capacity because the information was selfreported. However, because the sample comprised community-dwelling elderly and those individuals with cognitive impairment were excluded from this study, the error resulting from self-reporting was most likely minimized. Another limitation is the lack of information on the accomplishment of the intervention, as well as on the development shown by the participants during activities, which might influence the cognitive and functional outcomes.

We conducted this study with community-dwelling elderly and found reduced functional capacity over a 6-month period. These results are relevant because such a short period of time was sufficient to identify the changes in the functional capacity of community-dwelling adults. Such functional decline was independent of sociodemographic factors in the case of the BADLs. These results might contribute to future planning that focuses on the prevention of disability.

The changes in functional capacity associated with definite tasks identified in the present study give additional support to the fact that aging cannot be equated to disability by default and calls 
for the attention of healthcare and rehabilitation professionals to the need for planning interventions aimed at maintaining the functional capacity of the elderly. The results showed that working and living alone are predictors of higher scores on scales of functional capacity. These results might guide rehabilitation professionals to specific areas of intervention, simultaneously stressing the relevance of keeping the elderly active within the community.

\section{Acknowledgments}

We thank the FIBRA Network and the elderly who participated in the present study.

\section{References}

1. Nogueira SL, Ribeiro RCL, Rosado LEFPL, Franceschini SCC, Ribeiro AQ, Pereira ET. Determinant factors of functional status among the oldest old. Rev Bras Fisioter. 2010;14(4):322-29. http://dx.doi.org/10.1590/ S1413-35552010005000019

2. Maciel ACC, Guerra RO. Limitação funcional e sobrevida em idosos de comunidade. Rev Assoc Med Bras. 2008;54(4):347-52. PMid:18719794. http://dx.doi. org/10.1590/S0104-42302008000400021

3. Maia FO, Duarte YA, Lebrao ML, Santos JL. Risk factors for mortality among elderly people. Rev Saúde Pública. 2006;40:1049-56. http://dx.doi.org/10.1590/ S0034-89102006005000009

4. Freedman VA, Martin LG, Schoeni RF. Recent trends in disability and functioning among older adults in the United States: a systematic review. JAMA. 2002;288:3137-46. http://dx.doi.org/10.1001/jama.288.24.3137

5. Alves LC, Leimann BCQ, Vasconcelos MEL, Carvalho MS, Vasconcelos AGG, Fonseca TCO, et al. A influência das doenças crônicas na capacidade funcional dos idosos do município de São Paulo, Brasil. Cad Saúde Pública. 2007;23:1924-30. http://dx.doi.org/10.1590/ S0102-311X2007000800019

6. Lino VTS, Pereira SRM, Camacho LAB, Ribeiro ST $\mathrm{F}^{\circ}$, Buksman S. Adaptação transcultural da Escala de Independência em Atividades da Vida Diária (Escala de Katz). Cad Saúde Pública. 2008;24(1):103-12. http:// dx.doi.org/10.1590/S0102-311X2008000100010

7. Lawton MP, Brody EM. Assessment of older people: self-maintaining and instrumental activities of daily living. Gerontologist. 1969;9(3):179-86. http://dx.doi. org/10.1093/geront/9.3_Part_1.179

8. Paixão CM Jr, Reichenheim ME. Uma revisão sobre instrumentos de avaliação do estado funcional do idoso. Cad Saúde Pública. 2005;21(1):7-19. http://dx.doi. org/10.1590/S0102-311X2005000100002

9. Purser JL, Fillenbaum GG, Pieper CF, Wallace RB. Mild Cognitive impairment and 10-year trajectories of disability in the Iowa established populations for epidemiologic studies of the elderly cohort.
JAGS. 2005;53:1966-72. PMid:16274380. http://dx.doi. org/10.1111/j.1532-5415.2005.53566.x

10. Maciel ACC, Guerra RO. Influência dos fatores biopsicossociais sobre a capacidade funcioanal de idosos residentes no nordeste do Brasil. Rev Bras Epidemiol. 2007;10(2):178-89. http://dx.doi.org/10.1590/ S1415-790X2007000200006

11. Brum PS, Forlenza OV, Yassuda MS. Cognitive training in older adults with Mild Cognitive Impairment - Impact on cognitive and functional performance. Dement Neuropsychol. 2009;3(2):124-31.

12. Oliveira DLC, Goretti LC, Pereira LSM. O desempenho de idosos institucionalizados com alterações cognitivas em atividades de vida diaria e mobilidade: estudo piloto. Rev Bras Fisioter. 2006;10(1):91-6. http://dx.doi.org/10.1590/ S1413-35552006000100012

13. Silva SLA, Viana JU, Silva VGPT, Dias JMD, Pereira LSM, Dias RC. Influence of Frailty and Falls on Functional Capacity and Gait in CommunityDwelling Elderly Individuals. Topics Geriatric Rehabil. 2012; 28(2):128-134.

14. Hernandez SSS, Coelho FGM, Gobbi S, Stella F. Effects of physical activity on cognitive functions, balance and risk of falls in elderly patients with Alzheimer's dementia. Rev Bras Fisioter. 2010;14(1):68-74. http://dx.doi. org/10.1590/S1413-35552010000100011

15. Brucki SMD, Nitrini R, Caramelli P, Bertolucci PHF, Okamoto IH. Sugestões para o uso do mini-exame do estado mental no Brasil. Arq Neuropsiquiatr. 2003;61(3-B): 777-81. PMid:14595482. http://dx.doi.org/10.1590/S0004-282X2003000500014

16. Baltes PB, Mayer KU, editors. The Berlin Aging Study: Aging from 70 to 100. New York: Cambridge University Press; 1999.

17. Ribeiro LHM, Neri AL. Exercícios físicos, força muscular e atividades de vida diária em mulheres idosas. Ciênc Saúde Coletiva. 2012;17(8):2169-80. http://dx.doi. org/10.1590/S1413-81232012000800027

18. Pagano M, Gauvreau K. Princípios de Bioestatística. São Paulo: Thomson; 2004.

19. Abreu MNS, Siqueira AL, Cardoso CS, Caiaffa WT. Ordinal logistic regression models: application in quality of life studies. Cad Saúde Pública. 2008;24(4):5581-91.

20. Rosa AA, Rosa RJ, Lanuez FV, Lanuez MV, Balsalobre G, Malosa L, et al. Características demográficas (sexo e idade) e as atividades básicas e instrumentais de vida diária em adultos e idosos saudáveis. ConScientiae. 2010;9:407-12.

21. Camargos MCS, Rodrigues RN, Machado CL. Idoso, família e domicílio: uma revisão narrativa sobre a decisão de morar sozinho. Rev Bras Estud Popul. 2011;28:217-30. http://dx.doi.org/10.1590/S0102-30982011000100012

22. Giatti L, Barreto SM. Saúde, trabalho e envelhecimento no Brasil. Cad Saúde Pública. 2003;19(3):759-71. http:// dx.doi.org/10.1590/S0102-311X2003000300008

23. Nunes DP, Nakatami AYK, Silveira EA, Bachion MM, Souza MR. Capacidade funcional, condições socioeconômicas e de saúde de idosos atendidos por equipes de Saúde da Família de Goiânia (GO, Brasil). Ciênc Saúde Coletiva. 2010;15:2887-98. http://dx.doi. org/10.1590/S1413-81232010000600026 
24. Virtuoso JF, Mazo GZ, Menezes EC. Urinary incontinence and perineal muscle function in physically active and sedentary elderly women. Rev Bras Fisioter. 2011;15:3107. http://dx.doi.org/10.1590/S1413-35552011005000014

25. Fiedler MM, Peres KG. Capacidade funcional e fatores associados em idosos do Sul do Brasil: um estudo de base populacional. Cad Saúde Pública. 2008; 24:409-15. PMid:18278288. http://dx.doi.org/10.1590/ S0102-311X2008000200020

26. Lebrão ML, Laurenti R. Saúde, bem-estare envelhecimento: o estudo SABE no município de São Paulo. Rev Bras Epidemiol. 2005;8(2):127-41. http://dx.doi.org/10.1590/ S1415-790X2005000200005

27. Lourenço RA, Veras RP, Ribeiro PCC. Confiabilidade teste-reteste do Mini-Exame do Estado Mental em uma população idosa assistida em uma unidade ambulatorial de saúde. Rev Bras Geriatr Gerontol. 2008;11(1):7-16.

28. Argimon IIL, Stein LM. Habilidades cognitivas em indivíduos muito idosos: um estudo longitudinal. Cad Saúde Pública. 2005;21(1):64-72. http://dx.doi. org/10.1590/S0102-311X2005000100008
29. Diniz BSO, Volpe FM, Tavares AR. Nível educacional e idade no desempenho no Miniexame do Estado Mental em idosos residentes na comunidade. Rev Psiquiatr Clin (São Paulo). 2007;34:13-17. http://dx.doi.org/10.1590/ S0101-60832007000100002

30. Yassuda MS, Silva HS. Participação em programas para a Terceira idade: impacto sobre a cognição, humor e satisfação com a vida. Estud Psicol. 2010; 27:207-14.

\section{Correspondence}

\section{Marcella Guimarães Assis}

Universidade Federal de Minas Gerais

Escola de Educação Física, Fisioterapia e Terapia Ocupacional Programa de Pós-graduação em Ciências da Reabilitação

Av. Antonio Carlos, 6627

CEP 31270-901, Belo Horizonte, MG, Brasil

e-mail: mga@ufmg.br 